American Journal of Economics and Business Administration 3 (1): 81-86, 2011

ISSN 1945-5488

(C) 2010 Science Publications

\title{
Student's Mobile Information Prototype for the Higher Education Environment
}

\author{
Naji Shukri Alzaza and Abdul Razak Yaakub \\ College of Arts and Sciences (Applied Science), University Utara Malaysia, \\ 06010 Sintok, Kedah
}

\begin{abstract}
Problem statement: M-learning is considered as the next form of e-learning using mobile technologies to facilitate education for teachers and learners. Students need to keep in touch with their education services anytime regardless the place. Engaging the m-learning services in the Malaysian higher education will improve the availability of education. This study discusses the development and user's evaluation of Student's Mobile Information Prototype (SMIP). The study aims to utilize mobile learning services to facilitate education for students in the higher education environment. Approach: The Design Science Research Methodology (DSRM) was adapted to develop the SMIP. The evaluation was conducted to determine users' perception on the usability aspect of the SMIP. Results: Results of user's evaluation on the SMIP indicate that most of the participants highly agreed on perceived usefulness, perceived ease of use, learn ability, functionality and didactic efficiency. Moreover, the results confirm that SMIP is useful for users to make their transactions easy, direct and successful, regardless of location and time. Conclusion: It is hoped that the findings of this study will encourage students to keep in touch with their education environment anywhere and anytime.
\end{abstract}

Key words: Mobile learning, mobile technology, mobile learning services system, e-learning service, Student's Mobile Information Prototype (SMIP), Design Science Research Methodology (DSRM), IrDA, Wireless Application Protocol (WAP), Integrated Development Environment (IDE), higher education environment

\section{INTRODUCTION}

Mobile technology has been widely used in many areas such as education, health, entertainment, marketing and banking. Engaging the m-learning survives in the Malaysian higher education environment will improve the availability of education. This meets the priority of Malaysian higher education strategy to brand the education. Moreover, highlighted that the number of international students in Malaysia had increased between 2006 and 2008 by 30\%.

Students who are off-campus or do not have internet access, through the conventional wire or wireless connection for some reasons such as traveling, need to conduct their learning. Moreover, students access or conduct their learning services when they are somewhere away from the campus (Kadirire, 2007); the provided conventional e-learning services require internet access through computers. Fortunately, Mobile technologies are considered a viable wireless alternative and could be an ideal solution (Kadirire, 2007) and it is creating an additional channel of education
(Triantafillou et al., 2006). Consequently, such form of technology (m-learning) has to be introduced to extend and enhance the services of e-learning as well as it has been considered as a viable alternative for online learning to be anywhere and anytime through utilizing the mobile phones services in the higher education environment.

Mobile Learning (m-learning) has coincided with the evolution of the era of online world (Downes, 2005). The rapid evolution of mobile technology leads to development of m-learning using wireless on mobile devices (Yordanova, 2007). Furthermore, the learning process evolves in parallel with the communication means development; it has developed from conventional face-to-face to become distance learning as well as e-learning (Keegan, 2002).

M-learning is an emerging form of e-learning that offers the opportunity for both teachers and students to interact with educational material and services using mobile devices, independent of time and space. Availability and innovations of mobile technology such as wireless infrastructure, high bandwidth and mobile devices moved e-learning to m-learning era (Triantafillou et al., 2006).

Corresponding Author: Naji Shukri Alzaza, College of Arts and Sciences (Applied Science),

University Utara Malaysia, 06010 Sintok, Kedah 
The concept of wireless is to access the information using wireless connection such as Wireless Fidelity (Wi-Fi) General Packet Radio Service (GPRS) Bluetooth as well as IrDA (Infrared Data Association). The main issues regarding wireless technology are the protocol used; the architecture of wireless media; the session life and the programming language to develop software using such technology.

Wireless Application Protocol (WAP) has a client and server approach (WapForum, 2002) that compounds wireless network and internet technology. In fact, the motivation for developing WAP was to extend Internet technologies to wireless networks, bearers and devices.

Mobile technologies: Many mobile applications provide rich personal services such as sending and viewing email, browsing the World Wide Web, viewing traffic and weather reports, watching movies and chatting with others.

According to survey conducted by Malaysian Communications and Multimedia Commission (MCMC, 2008) in 2007, Malaysian adults (users aged between 20 and 49 years) represented the highest group of users $(66.8 \%)$ followed by $20.9 \%$ pre-teens and teens (users aged up to 19 years old). Seniors (aged 50 years and above) represented only $12.3 \%$.

However, (MCMC, 2008) survey investigated mobile services used by Malaysian's users in 2007 indicates that the most popular financial transaction was payment of bills (72.4\%), followed by remittance (person to person transfers) $34.5 \%$ and purchase of mobile ring tones, top-up as well as games. The hotspot number grows constantly in most of Malaysian states, for instance, in Perlis State, it increased from 43 hotspots in 2006 to reach 111 in 2007, in the same duration, Kedah State increased from 31 hotspots to 56 and Perlis State from no hotspot in the first quarter of 2007 to 2 hotspots in the fourth quarter of the same year (MCMC, 2008).

M-learning definition has been on the focus of scholars attention; Moura and Carvalho (2003) defined m-learning as an extension of distance learning supported by wireless mobile technologies, Trifonova and Ronchetti (2003) defined it as e-learning through mobile computational devices. Defined m-learning as the intersection of mobile computing and e-learning: in terms of accessible resources wherever you are; strong search capabilities, rich interaction; powerful support for effective learning; and performance-based assessment. Thus, M-learning is considered as the next form of e-learning using mobile technologies to facilitate education for teachers and learners anywhere and anytime.
Nevertheless, several scholars went on to discuss the vision rather than definition. According to COSMOTE (COS, GR) (2006); The future of mlearning is to support creation, brokerage, delivery and tracking of learning and information contents; location-dependence, personalization, multi-media, instant messaging and distributed databases.

Several studies reveal the capabilities and limitations of e-learning (Nasiri and Deng, 2009). They state that there are great similarities between e-learning and m-learning, one may represent the other with new platform and more sophisticated technologies.

Barker et al. (2005) indicated that m-learning is emerging as a portable solution that enables learners to engage in collaborative and interactive learning activities. They argued that using m-learning is appropriate to support group work on projects, engage learners in learning-related activities in diverse physical locations and to enhance communication and collaborative learning in the classroom.

Mobile learning services: Mobile learning services have been increased through the capability of the mobile technology itself. However, Georgieva et al. (2005) investigated the m-learning systems and classified them into seven divisions based on mobile devices and their capabilities; communication technology used; communication between students and lecturers; access of services whether online or offline (Rekkedal and Dye, 2007); the location of learners; information which comprise learning materials and administrative information; and e-learning standards whether supported or not.

Rekkedal and Dye (2007) determined acceptable m-learning solutions that access and interact with university learning materials and for lecture-student, student-lecture and student-student communication. They depended on the view states that "learning is an individual process that can be supported by adequate interaction and/or collaboration in groups".

Corlett et al. (2005) investigated the student side of m-learning while Seppala et al. (2002) investigated teacher side. However, both studies argue that mobile technology offers an opportunity to improve the students learning experience and to provide a new dimension to acquire more knowledge during studying period. In addition, they indicated that teachers and students need more training on the use of mobile technology in order to achieve the maximum benefit introduced for education.

Although Corlett et al. (2005) found that only a few students used the Personal Digital Assistant (PDA) for their own personal activities, students had adapted them with mobile technology capabilities through the using time. 
Am. J. of Economics and Business Administration 3 (1): 81-86, 2011

Despite Meng et al. (2004) provided a vital idea that enables mobile developers to transform conventional web pages into mobile web pages. However, their study needs more enhancements since they used an old technology that depends on Java Applet, which is not widely used in mobile devices like smart phones. Alzaza and Zulkifli (2007) provided a prototype that helps students to access library loan services through mobile devices. They found that there is a significant difference between novice and expert users for Usefulness and Ease of Use, while no significant difference for Outcome/Future Use of their prototype.

Kadirire (2007) provided an Instant Message (IM) prototype that enables students to communicate with each others. The prototype detects various types of mobile devices then adapts the content to fit the particular devices capability. Kadirire (2007) argued that IM is becoming widespread in universities and is encouraging learners to become more engaged with their courses. However, IM is now being used for online discussions, chatting, file transfer, library access and usage. Some of the widely used IM applications are AOL Instant Messenger, MSN Messenger, Yahoo Messenger, Google Talk and Skype.

Sharples et al. (2002) aimed to design humancentered systems that are based on sound understanding of how people think, learn, perceive, study, communicate and interact. The participants of evaluation suggested improving the interface of prototype and stated some hardware problems that include device weight and short battery life.

\section{MATERIALS AND METHODS}

The Design Science Research Methodology (DSRM) was adapted to develop the SMIP. DSRM was chosen to precede the research because it emphasizes the knowledge generation inherent in the method of development. DSRM was proposed by Vaishnavi et al. (2007). Figure 1 illustrates DSRM's phases that comprise awareness of problem, Suggestion, development, evaluation and conclusion.

Development of Student's Mobile Information Prototype (SMIP): SMIP was developed based on the Wireless Application Protocol (WAP) using Microsoft Visual CA.NET. It was completely developed with .NET Framework using ASP. NET 2.0 as Integrated Development Environment (IDE).

Figure 2 illustrates the SMIP architecture. Student can access the SMIP through the wireless media using his/her mobile phone, PDA, or smart phone.

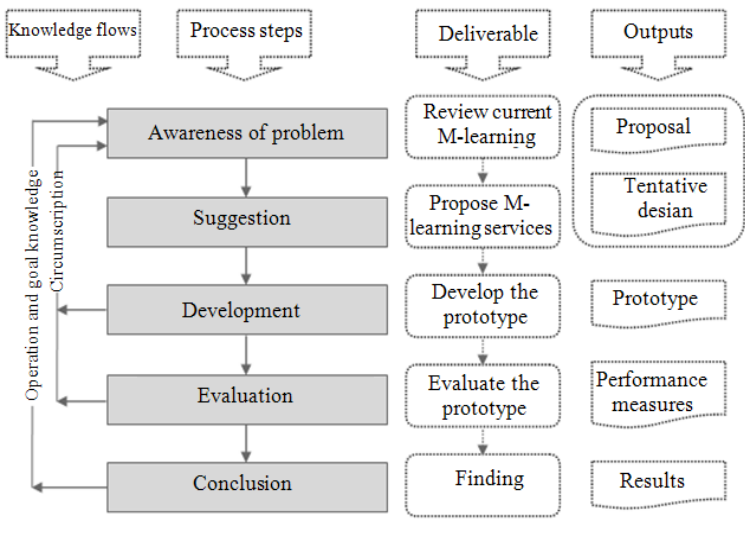

Fig. 1: Framework of Adapted DSRM methodology

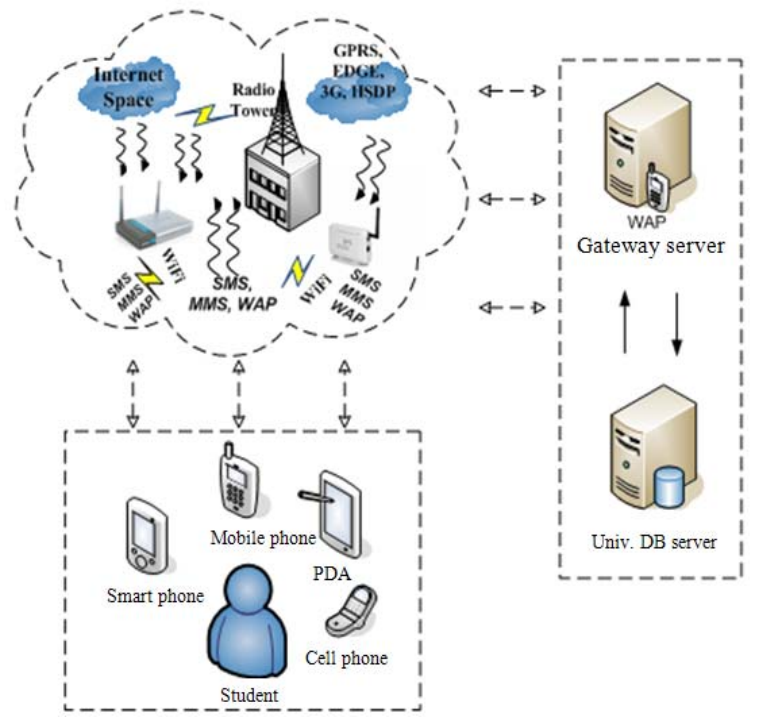

Fig. 2: Student's Mobile Information Prototype (SMIP) Architecture

The limitation of mobile phones and communication were considered when designing the SMIP. The navigation hyperlinks were anchored in the bottom of each page; information displays, selected carefully to meet the small screen of mobile phones and to reduce the scrolling down; size of the header image is less than 3.5 bytes to reduce the download cost and to avoid the low speed of network connectivity; in addition, list boxes, radio buttons and hyperlinks were used to reduce the key-in inputs and to avoid the weakness of mobile phones input capabilities.

SMIP provides eight main services comprises course announcement, exam result, instructor profile, course registration, finance statement, calendar, student profile 


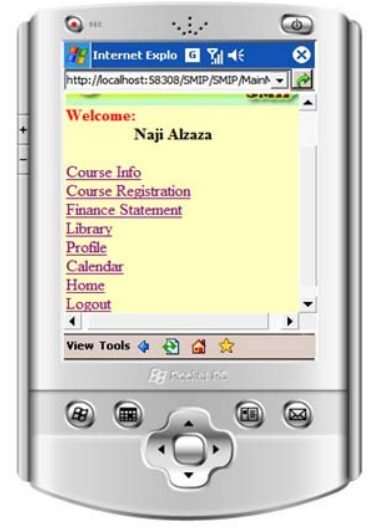

(a)

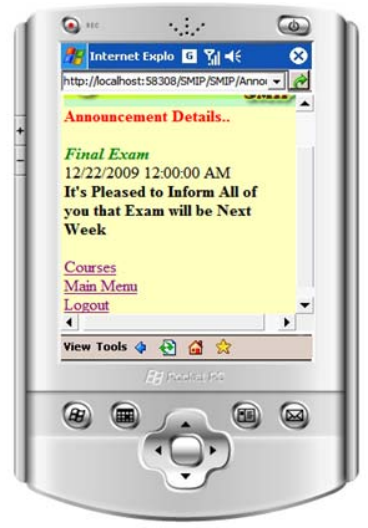

(b)
Fig. 3:(a) Snapshot of welcome page and (b) Snapshot of Announcement page

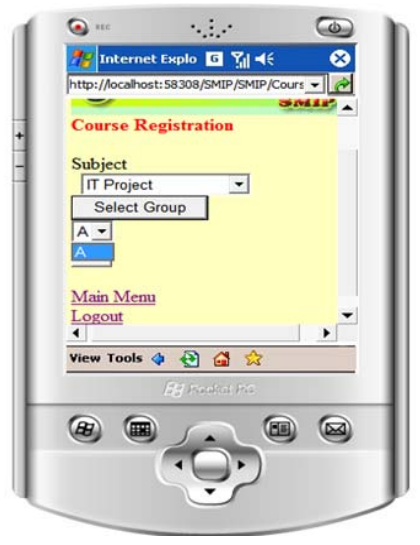

Fig. 4: Snapshot of course registration service

and library loan services. The navigation hyperlink button of each page enables student to navigate easily, through and between SMIP pages. Snapshot (a) of welcome page shown in Fig. 3 is the main page that enables student to navigate all SMIP services. Snapshot (b) shows the announcement details page.

Snapshot in Fig. 4 shows the course registration service. SMIP listed the subjects that are allowed for registration based on student's academic plan and the current semester schedule.

User evaluation: The evaluation was conducted to determine users' perception on the usability aspect of the prototype. Usability is considered an important attribute of software quality. It is concerned with making systems easy to learn and easy to use. The instrument was adapted from Rekkedal and Dye (2007); Lewis (1995); Zins et al. (2004) and Davis (1989). After the survey was developed, it was piloted and some minor changes were made. The instrument comprises two parts which are general information and dimensions of user evaluation. General information part works as a mechanism to collect users' demographic data, users' experience and knowledge with the mobile applications. The instrument dimensions of adaptive user evaluation comprise four parts: System usefulness; information quality, interface quality and system efficiency. A 5-point Likert scale anchored by "Strongly Disagree" (1) and Strongly Agree (5) was used.

The SMIP user evaluation was conducted on fifty four respondents. Each of them was given brief explanation regarding the usage and the user interface of the prototype. Each user was allocated a proper time to use and explore the content of the prototype. Once they were done, users were given a questionnaire for user evaluation. Descriptive statistics, reliability analysis and t-test were used in this study. SPSS version 14 was used to analyze the data. Results from the descriptive, reliability and t-test analyses will be discussed in the following results.

\section{RESULTS AND DISCUSSION}

A sample of 54 random selected students' response. As shown in the Table 1, 51.9\% of respondents were male and $48.1 \%$ female, majority of respondents $(94.4 \%)$ were aged between 20 and 25 years old. While business studies made up the largest group of respondents $(75.9 \%)$, science studies were $18.5 \%$. art studies were only $5.6 \%$. In terms of education level, most of respondents were in bachelor level (98.1\%). $92.6 \%$ of the participants declared that they own mobile phone and $5.6 \%$ own smart phone, only $1.9 \%$ own PDA. Regarding mobile application experience $50 \%$ have experience between 5 and 9 years; $44.4 \%$ have less than 5 years of use the mobile application experience; while only 5.6 have more than or equal 10 years. This indicates that the respondent of mobile application experience is respectable.

Table 2 presents the Cronbach alpha $(\alpha)$ value for each measure. All measures have Cronbach alpha of greater than 0.7 thus, these measures satisfy the internal reliability criterion (Pallant, 2007).

The ranges of five point Likert-scales were categorized into equal sized categories of low, moderate and high. Therefore, score of less than 2.33 [4/3+ lowest value (1)] are considered low; scores of 3.67 [highest value (5)-4/3] are considered high and those in between are considered moderate. Five of measures with high means are bolded which indicate that most of the participants highly agreed on perceived usefulness, perceived ease of use, learn ability, functionality and didactic efficiency. Overall, the results indicate that the participants agreed that SMIP has appropriate usability. 
Am. J. of Economics and Business Administration 3 (1): 81-86, 2011

Table 1: Demographic data of students

\begin{tabular}{llrrr}
\hline Measure & Item & $\mathrm{N}$ & \multicolumn{1}{c}{ (\%) } & \multicolumn{1}{c}{$\begin{array}{c}\text { Cumulative } \\
(\%)\end{array}$} \\
\hline Gender & Male & 28 & 51.9 & 51.9 \\
& Female & 26 & 48.1 & 100.0 \\
Age & Below 20 & 3 & 5.6 & 5.6 \\
& $20-25$ & 51 & 94.4 & 100.0 \\
& $26-30$ & 0 & 0.0 & 100.0 \\
& $31-35$ & 0 & 0.0 & 100.0 \\
Education & $36-40$ & 0 & 0.0 & 100.0 \\
& More than 40 & 0 & 0.0 & 100.0 \\
Education level & Science & 10 & 18.5 & 18.5 \\
& Business & 41 & 75.9 & 94.4 \\
Mobile & Art Studies & 3 & 5.6 & 100.0 \\
devise type & Bachelor & 53 & 98.1 & 98.1 \\
& Master & 0 & 0.0 & 98.1 \\
Mobile & PhD & 1 & 1.9 & 100.0 \\
application experience & PDA & 1 & 1.9 & 1.9 \\
& Smart Phone & 3 & 5.6 & 7.4 \\
& Hand Phone & 50 & 92.6 & 100.0 \\
& 9-May & 24 & 44.4 & 44.4 \\
& $>=10$ Years & 27 & 50.0 & 94.4 \\
& & 5.6 & 100.0 \\
\hline
\end{tabular}

Table 2: Cronbach alpha values for all dimensions

\begin{tabular}{llll}
\hline Variable & Number of items & Mean & Alpha $(\alpha)$ \\
\hline Perceived usefulness & 6 & 3.809 & 0.94 \\
Perceived ease of use & 6 & 3.833 & 0.93 \\
Learn ability & 3 & 3.778 & 0.70 \\
Information quality & 7 & 3.585 & 0.91 \\
Functionality & 4 & 3.676 & 0.90 \\
Errors/system reliability & 2 & 3.315 & 0.78 \\
Outcome/future use & 6 & 3.639 & 0.94 \\
Interface quality & 4 & 3.579 & 0.90 \\
Design/layout & 3 & 3.531 & 0.93 \\
Didactic efficiency & 4 & 3.722 & 0.89 \\
Cost effectiveness & 3 & 3.463 & 0.79 \\
\hline
\end{tabular}

Impact of mobile experience on levels of measurements: A one-way Analysis of Variance (ANOVA) between groups was conducted to explore the impact of Mobile Experience on levels of perceived usefulness, perceived ease of use, learn ability, information quality, functionality, errors/system reliability, outcome/future use, interface quality, design/layout and didactic efficiency and cost effectiveness. The results of the test of three mobile applications experience groups indicated that there was no statistically significant difference in the mean of all measurements by mobile experience of respondents.

\section{CONCLUSION}

Student's Mobile Information Prototype (SMIP) was developed to facilitate education for students of higher education environment, using mobile technology anywhere and anytime. The prototype was evaluated and the results confirm that it is useful for users to make their transactions easy, direct and successful, regardless of location and time. It is hoped that the findings of this study will encourage students in the higher education institutions to keep in touch with their education environment anywhere and anytime.
However, M-learning is the future of education, with its own characteristics, that make it capable of rapid evolution in information technology. Moreover, using mobile wireless technology in higher education will keep growing and will become the choice of the learning environment.

\section{REFERENCES}

Alzaza, N.S. and A.N. Zulkifli, 2007. Mobile Based Library Loan Service (MBLLS). Proceeding of the Rural ICT Development Conference, Nov. 20-21, Executive Development Centre (EDC), Sintok, Malaysia, pp: 1-8. http://najishukri.files.wordpress.com/2010/05/pape rmblls.pdf

Barker, A., G. Krull and B. Mallinson, 2005. A proposed theoretical model for m-learning adoption in developing countries. Proceeding of the Mobile technology: The future of learning in your hands, October 25-28, Cape Town, South Africa, pp: 1-10.

Corlett, D., M. Sharples, T. Chan and S. Bull, 2005. A mobile learning organiser for university students. J. Comput. Assisted Learn., 21: 162-169. DOI: 10.1111/j.1365-2729.2005.00124.x

COSMOTE (COS, GR), 2006. The Mobilearn. Mobilearn Consortium. http://www.mobilearn.org/partners/consortium/part ner_list/cosmote.htm

Davis, F., 1989. Perceived usefulness, perceived ease of use and user acceptance of information technology. Int. J. Human-Comput. Interaction, 7: 57-78.

Downes, S., 2005. Feature: E-learning 2.0. eLearn Magazine.

http://elearnmag.org/subpage.cfm?section=articles \&article $=29-1$

Georgieva, E., A. Smrikarov and T. Georgiev, 2005. A general classification of mobile learning systems. Proceeding of the International Conference on Computer Systems and TechnologiesCompSysTech, June 16-17, Varna, Bulgaria, pp: 11-16.

Kadirire, J., 2007. Instant messaging for creating interactive and collaborative m-learning environments. Int. Rev. Res. Open Distance Learn., 8: $1-14$.

Keegan, D., 2002. The future of learning: From eLearning to mLearning. 1st Edn., Zentrales Institut für Fernstudienforschung, Germany: FernUniversitat, pp: 172.

Lewis, J.R., 1995. IBM computer usability satisfaction questionnaires: psychometric evaluation and instructions for use. Int. J. Human-Comput. Interaction, 7 : 57-78. $\quad$ DOI: $10.1080 / 10447319509526110$ 
MCMC, 2008. Hand Phone Users Survey 2007 annual survey on hand phone users. Cyberjaya, Selangor Darul Ehsan, Malaysia.

Meng, Z., J. Chu and L. Zhang, 2004. Collaborative learning system based on wireless mobile equipments. Elec. Comput. Engineer., 1: 481-484.

Nasiri, A. and G. Deng, 2009. Environmental factors influence on mobile learning business. Am. J. Applied Sci., 6: 1225-1234. DOI: 10.3844/ajassp.2009.1225.1234

Pallant, J., 2007. SPSS Survival Manual: A Step by Step Guide to Data Analysis Using SPSS. 3rd Edn., Open University Press, Wellington, New Zealand, pp: 352 .

Rekkedal, T. and A. Dye, 2007. Mobile distance learning with PDAs: Development and testing of pedagogical and system solutions supporting mobile distance learners. Int. Rev. Res. Open Distance Learn., 8: 51-74.

Seppala, P., J. Sariola and H. Kynaslahti, 2002. Mobile learning in personnel training of university teachers. Proceeding of the IEEE International Workshop on Wireless and Mobile Technologies in Education, Aug. 29-30, IEEE Xplore Press, Vaxjo, Sweden, pp: 136-139.

Sharples, M., D. Corlett and O. Westmancott, 2002. The design and implementation of a mobile learning resource. Personal Ubiquitous Comput., 6: 220-234. DOI: 10.1007/s007790200021
Triantafillou, E., E. Georgiadou and A.A. Economides, 2006. CAT-MD: Computer Adaptive Test on Mobile Devices. Paper presented at the IV International Conference on Multimedia and ICTs in Education, Nov. 29-2 Dec., Seville, Spain, pp: 773-777.

Trifonova, A. and M. Ronchetti, 2003. Where is mobile learning going? Proceeding of the E-Learn 2003 Conference, (ELC'03), Phoenix, AZ, USA., pp: 1794-1801.

Vaishnavi, V., V.K. Vaishnavi and W. Kuechler, 2007. Design Science Research Methods and Patterns: Innovating Information and Communication Technology. 1st Edn., Auerbach Publications, New York, pp: 226.

WapForum, 2002. What is WAP Open Mobile Alliance Ltd. http://www.wapforum.org/faqs/index.htm

Yordanova, K., 2007. Mobile learning and integration of advanced technologies in education. Proceeding of 2007 the International Conference on Computer Systems and Technologies, ACM, New York, pp: 21-26.

Zins, A.H., U. Bauernfeind, F. Del Missier and H. Rumetshofer, 2004. An experimental usability test for different destination recommender systems. Proceeding of the International Conference in Information and Communication Technologies In Tourism, (ICTT' 04), Springer, Cairo, Egypt, pp: 249258. http://www.modul.ac.at/node/816 